\title{
Charity Care, Risk Pooling, and the Decline in Private Health Insurance
}

\section{Citation}

Chernew, Michael, David Cutler, and Patricia Keenan. 2005. Charity Care, Risk Pooling, and the Decline in Private Health Insurance. American Economic Review 95(2): 209-213.

\section{Published Version}

http://dx.doi.org/10.1257/000282805774669600

\section{Permanent link}

http://nrs.harvard.edu/urn-3:HUL.InstRepos:2640562

\section{Terms of Use}

This article was downloaded from Harvard University's DASH repository, and is made available under the terms and conditions applicable to Other Posted Material, as set forth at http:// nrs.harvard.edu/urn-3:HUL.InstRepos:dash.current.terms-of-use\#LAA

\section{Share Your Story}

The Harvard community has made this article openly available.

Please share how this access benefits you. Submit a story.

Accessibility 


\title{
INSURANCE MARKETS AND HEALTH CARE ${ }^{\dagger}$
}

\section{Charity Care, Risk Pooling, and the Decline in Private Health Insurance}

\author{
By Michael Chernew, David Cutler, and Patricia Seliger Keenan*
}

Over the past several decades health-care costs have increased substantially, and the share of the population with insurance coverage has decreased. Relative to GDP, medical care today accounts for 75 percent more of the economy than it did in 1980. At the same time, the share of the non-elderly population that is uninsured has increased by roughly 4 percentage points since 1987. To what extent is the increase in the cost of health insurance responsible for the decline in coverage?

Individuals will purchase coverage if the utility of being insured exceeds that of being uninsured. Textbook economic theory suggests that rising medical expenditures ought to increase the utility of coverage because insurance mitigates risk. If the variability of spending rises as

\footnotetext{
† Discussants: Amitabh Chandra, Dartmouth College; Ellen Meara, Harvard Medical School; Helen Levy, University of Chicago; Darius Lakdawalla, RAND Corporation.

* Chernew: Department of Health Management and Policy and Department of Economics, University of Michigan, Ann Arbor, MI 48109-2029; Cutler: Department of Economics, Harvard University, Cambridge, MA 02138; Keenan: NBER, Cambridge, MA 02138. This work was funded by the Economic Research Initiative on the Uninsured, the National Institute on Aging, and the Sloan Foundation. Keenan gratefully acknowledges support from the National Institute on Aging, grant no. T32-AG00186. We thank Laurence Baker for sharing HMO penetration data, Dan Feenberg for providing tax data from NBER TAXSIM, Clifton Maze for providing Medicare spending data and supporting information, Jean Roth for assistance with reading in Medicare spending and CPS files, Kosali Simon for sharing state regulation data, Jon Gabel for providing access to KPMG and KFF/HRET Survey of Employer-Sponsored Health Benefits data, Reagan Baughman for sharing data regarding Medicaid eligibility, Jill Horwitz for sharing AHA data, Dick Merritt and Kosali Simon for sharing IHPP reports, and Amy Finkelstein, Bradley Herring, Srikanth Kadiyala, Willard Manning, Len Nichols, Joe Newhouse, Sarah Reber, Kathy Swartz, Vivian Wu, and Chapin White for helpful conversations. We also acknowledge helpful comments from seminar participants at Duke University, Stanford University, RAND Corporation, and the NBER.
}

medical care costs increase, insurance becomes more valuable (Charles Phelps, 1997). ${ }^{1}$ The rising demand for pharmaceutical coverage following the rise in spending on pharmaceuticals is consistent with this model. In the textbook model, rising costs would be associated with falling coverage only if the cost increases were driven by increased administrative loads. Empirically, though, most medical spending is a result of increased quantities of care received, owing to technological changes in medicine, not greater administrative burden (Cutler and Mark McClellan, 2001).

There are two extensions to the textbook model that can help explain the inverse relationship between premiums and insurance coverage. The first is the hypothesis that the value of new services is not sufficiently high to justify their costs, and thus some people rationally decline coverage when costs increase. ${ }^{2}$ Of course, if consumers had the option, they would exclude unvalued care from the insurance policy, but determining which care is valuable and which is not may be difficult, and contracting imperfections may make it difficult for individuals to purchase a plan that limits access to particular services.

One type of unvalued care is traditional moral hazard: services are provided because of insurance but are worth less than they cost. Cutler (2004) shows that increased medical spending overall has bought care that is more than worth its value. But that does not imply that the differential growth of service use in some areas

\footnotetext{
${ }^{1}$ This need not be true in all contexts; the mean of spending could increase while the spread narrows. However, if technology increases spending proportionately at each point in the distribution, or disproportionately affects spending for the very sick, greater spending would be associated with greater variance.

${ }^{2}$ Rising quantities of care function, in essence, as an increase in administrative loads.
} 
of the country relative to other areas is purchasing services of high value. It may be that highcost growth areas are disproportionately buying care with little marginal value.

A more subtle story about the value of care concerns the breakdown of risk pooling. Insurance is generally not priced at the individual level. Most insurance is bought in employment groups. Although there may be a group-specific wage offset associated with coverage (Louise Sheiner, 1997; Mark V. Pauly and Bradley Herring, 1999), it is likely that relatively healthy groups of individuals would experience a greater increase in premiums, compared to the value they receive, relative to less healthy individuals. As a result, the healthy could decide to drop coverage as technological change improves care for the sick. Why should a relatively healthy 30 -year-old pay 10 percent more each year for insurance if most of the costs are for services that are very unlikely to be used? The result is the potential for market unraveling.

The second extension to the textbook model focuses on the utility of being uninsured, stressing the availability of charity care for the uninsured as a mechanism for avoiding the increased costs of coverage (Kevin Rask and Kimberly Rask, 2000; Herring, 2001). People who are uninsured do not pay for all medical care outof-pocket. Rather, much of the care is "uncompensated," written off by the provider as bad debt or charity care. While evidence suggests that a lack of coverage is associated with worse health outcomes (Institute of Medicine, 2002), the incremental value of the access to care associated with coverage may not be rising as rapidly as costs over time if the new technology is at least partly integrated into charity care. We examine these possible explanations for the relationship between premiums and coverage in the next sections of the paper.

\section{Medical Costs and Insurance Coverage}

To examine the factors predicting changes in insurance coverage, we use data on coverage in different metropolitan statistical areas (MSAs) at the beginning and end of the 1990s. ${ }^{3}$ We create two cohorts of non-elderly individuals

\footnotetext{
${ }^{3}$ See Chernew et al. (2004) for discussion of the data and its construction.
}

from the Current Population Survey (CPS): one cohort from 1988-1990 and the second from 1997-1999. Respondents are divided into health insurance units (HIUs), the typical unit in which insurance is purchased. The CPS provides a rich array of HIU and market-level variables that we control for, including basic demographics, income, employment characteristics, and MSA characteristics such as the overall demographic composition. As discussed below, we use age as a proxy for health status.

We measure health insurance premiums using premium data from the Health Insurance Association of America and the Kaiser Family Foundation/Health Research and Educational Trust Survey of Employer-Sponsored Health Benefits (KPMG Survey, 1988, 1989, 1998; and Kaiser Family Foundation, 1999). Surveys are pooled from 1988 and 1989 for the early years and 1998 and 1999 for the later years. To purge the premium data of differences in benefit design, we regress premiums on plan type, whether an employer offers multiple plans, and interactions of these variables with each other and year dummies; cost-sharing parameters such as deductible, coinsurance, and copay amounts; dummy variables for service coverage, including coverage for prescription drugs, outpatient mental-health benefits, inpatient mental-health benefits, and maternity benefits; firm size and industry dummies; and MSA dummies and their interaction with years. The coefficients on MSA dummies in this regression give adjusted premium estimates at the MSA level. ${ }^{4}$ Premiums have increased substantially over time. From the late 1980s to the late 1990s, the cost of a standard insurance policy for an individual increased by $\$ 818$ (in 1999 dollars).

Clearly, premium changes may be endogenous to changes in insurance coverage, and measurement error in the premium data can bias the estimates. Yet in Chernew et al. (2005) we report that in models for any insurance coverage, instrumental-variables models using per capita MSA level Medicare Part B spending and state-level personal spending for the non-elderly as instruments for premiums were even a bit

\footnotetext{
${ }^{4}$ The coefficients from this regression indicate that more generous benefits led to greater premiums; the $R^{2}$ from this regression was 0.26 . The resulting premium estimates are quite reasonable: the correlation between adjusted premiums and Medicare Part B spending at the MSA level is 0.47.
} 
larger than ordinary least-squares estimates (presumably because of measurement error).

We measure charity-care availability as the number of public and teaching hospital beds per capita, from American Hospital Association data. ${ }^{5}$ These are the hospitals that provide much of charity care in the United States (Joyce Mann et al., 1997). We measure these variables only in 1990 to minimize reverse causality issues that may arise because these measures could be affected by insurance, rather than the reverse. The average area had 0.0013 public and teaching hospital beds per capita in 1990 . We also include the share of children eligible for Medicaid, following Cutler and Jonathan Gruber (1996). A lengthy literature has focused on public insurance crowd-out, finding significant evidence that Medicaid eligibility reduces private coverage.

We control for several other variables suggested in the literature that might lead to decreased levels of insurance. Traditional theories of insurance have focused on the tax price of insurance: marginal tax rate reductions over the past two decades have lowered the tax subsidy to health insurance purchases, and thus possibly led to reduced coverage. We measure the tax subsidy for health insurance along the lines of Gruber (2001). We also control for state regulations that could affect coverage, specifically whether a state has passed insurance rating reforms or enacted guaranteed issue for the smallgroup health insurance market (Kosali Simon, 2000). Finally, some have hypothesized that a greater share of working women should lead to lower insurance coverage, as employers provide less generous benefits in the hope of encouraging employees to take up coverage elsewhere (David Dranove et al., 2000; Henry S. Farber and Helen Levy, 2000).

Estimates from a model of coverage without a premium $\times$ charity-care interaction suggest that a $\$ 1,000$ increase in premiums reduces the propensity to purchase private coverage by 2.7 percentage points (standard error $=0.007$ ). ${ }^{6}$

\footnotetext{
${ }^{5} \mathrm{We}$ include this variable as an interaction with time period, to examine whether the effect of charity-care availability changes over time.

${ }^{6}$ We use linear probability models throughout the paper for ease of interpretation, and to avoid issues of different magnitudes of the effect based on the baseline characteristics (Chunrong Ai and Edward C. Norton, 2003). Nonlinear
}

The premium coefficient is statistically significantly different from zero. Further, it is large. The $\$ 818$ per person increase in the cost of a single policy over the past decade can account for about two-thirds of the total 3.3-percentagepoint reduction in private insurance coverage over the time period.

The estimates on the other covariates are generally consistent with the existing literature (results available from the authors upon request). A higher tax price discourages private coverage. Individuals in markets with a larger share of working women and with greater Medicaid generosity or charity-care providers are less likely to have private coverage, consistent with the public health insurance crowd-out literature.

\section{Charity Care and Administrative Loads}

We examine the reasons why increased premiums affect insurance coverage in several ways. To explore the charity-care explanation, we interact the measure of public and teaching hospital availability with premiums. ${ }^{7}$ The charitycare explanation suggests that premiums should have a larger effect on coverage when charity care is more readily available. In this regression, the coefficients on premiums and their interaction with charity care are $-0.019(\mathrm{SE}=0.008)$ and $-13.10(\mathrm{SE}=5.81)$, respectively. The results are consistent with the theory: the responsiveness to private coverage from premiums is nearly twice as great at the mean value of charity care, as compared to if charity care is not available. Put another way, about half of the impact of rising premiums on insurance coverage is a result of the availability of charity care.

The charity-care explanation should be more important for groups with low income and assets, since these groups cannot contribute as much of their own funds to paying for care. The magnitudes of the responsiveness to premiums are depicted in Figure 1 for subgroups by age, education, and income based on separate

estimation methods such as probit give similar results with a somewhat higher effect of premiums on coverage declines. The standard errors in all cases are adjusted for intra-MSA correlation.

${ }^{7}$ We also estimated the interaction between premiums and Medicaid eligibility. We do not find a greater response to premiums in areas with greater Medicaid eligibility. 


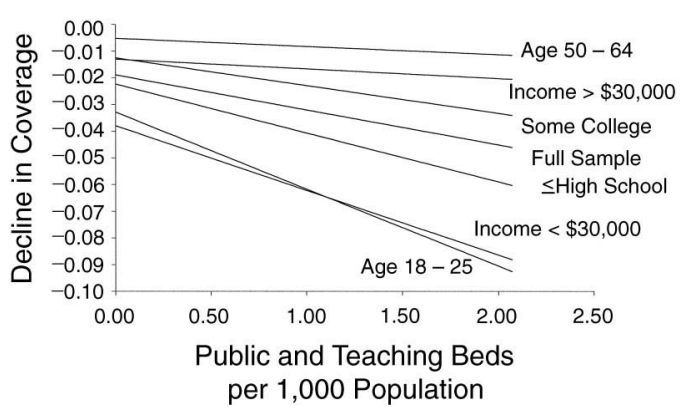

Figure 1. Impact of Premiums on Coverage: The EFFECTS OF CHARITY CARE

Notes: The vertical axis is the percentage-point decline in coverage per $\$ 1,000$ increase in premium.

models by subgroup (Table 1 ). The results are again consistent with the theory. The impact of premiums themselves (and of the charity-care interaction) is much greater for less-educated (full results available from the authors upon request) and lower-income populations. ${ }^{8}$ Indeed, we find no evidence that premium increases reduce coverage among the group with some college or more education, or those with incomes above $\$ 30,000$ per year.

The risk-pooling explanation suggests looking at the response by health status: increased premiums should have a greater impact for the healthy than for the less healthy. We proxy for health status using age: people aged 18-25 are on average much healthier than those aged 5064. The risk-pooling explanation also finds empirical support. Premium increases substantially reduce coverage among the healthier population and have no impact on coverage among the older population. The decline in coverage for the healthy is particularly true in areas where charity care is more readily available, suggesting an interaction between our risk-pooling and charity-care theories.

While this evidence is consistent with the risk-pooling explanation, it might also be consistent with other theories, including models where the young view new services as less valuable than the old, or where the young are less risk-averse than the old. We would need direct measures of perceived value and of risk aversion to differentiate among all these theories.

\footnotetext{
${ }^{8}$ The same is true about the availability of Medicaid.
}

Table 1-Linear Probability Models Explaining Private Health-Insurance Coverage

\begin{tabular}{lcc}
\hline \hline Income & $\leq \$ 30,000$ & $>\$ 30,000$ \\
\hline Premiums $^{\mathrm{a}}$ & $-0.038^{* *}$ & -0.013 \\
& $(0.014)$ & $(0.008)$ \\
Charity-care premium $^{\dagger}$ & $-24.24^{*}$ & -3.65 \\
& $(10.71)$ & $(4.83)$ \\
& & \\
Age & $18-25$ & $50-64$ \\
\hline Premiums $^{\mathrm{a}}$ & $-0.033^{\dagger}$ & -0.005 \\
& $(0.017)$ & $(0.014)$ \\
Charity care premium $^{\dagger}$ & $-28.85^{*}$ & -3.07 \\
& $(11.14)$ & $(11.28)$ \\
\hline
\end{tabular}

Notes: Each set of coefficients represents a separate regression. All models include MSA fixed effects and control for individual demographics as well as the level of charity care, tax price, state insurance reforms, Medicaid generosity, percentage working women, and market-level demographics such as percentage foreign born, MSA unemployment, mean MSA family income, percentage elderly, and percentage nonwhite. Robust standard errors are reported in parentheses.

${ }^{\text {a }}$ Thousands of dollars.

Statistically significant at the 10-percent level.

* Statistically significant at the 5-percent level.

** Statistically significant at the 1-percent level.

The fact that premiums have no impact on coverage for older, better educated, and higherincome populations is consistent with the idea that there is no pure moral hazard in rising health-care costs - that is, the additional care bought is clinically useful. However, the impact of the tax price, a measure of pure load, is also not very salient in the older population, suggesting that this group is very risk-averse and perceives the value of coverage relative to relying on charity care to be substantial.

\section{Summary}

The evidence is clear that rising health-insurance costs lead to significant reductions in insurance coverage-as much as two-thirds of the overall decline in coverage in the 1990s. We estimate that up to half of this response to higher costs is related to the availability of charity care. This estimate is rough because our estimates of the availability of charity care are based solely on the availability of beds in public and teaching hospitals. Moreover, our charitycare measure, which incorporates availability of beds in teaching hospitals, could reflect greater moral hazard over time. Nevertheless, the mod- 
els consistently demonstrate that the availability of beds in facilities that are relied upon for charity care increases the sensitivity of coverage to rising premiums. By providing access for the uninsured, charity-care providers inadvertently create the conditions for crowding out of private health insurance.

We suspect that the remaining impact of premiums on coverage is due to diminished utility of coverage associated with rising premiums, particularly for the young and for low income individuals. The evidence we present is consistent with this, although not definitive. Of particular importance may be the pooling of high- and low-risk enrollees, which leads to identifiable transfers from the healthy to the sick. As medical costs increase, the size of these transfers rises, and the willingness of the healthy to make them declines.

The new era of rising medical spending we have recently entered could have a major impact on private insurance coverage. Moreover, the decline in coverage caused by rising premiums will place a greater burden on charity-care providers. Though important in a time of declining coverage, bolstering the strained charity-care system may further exacerbate the decline in coverage, posing a policy dilemma in responding to increases in the uninsured population.

\section{REFERENCES}

Ai, Chunrong and Norton, Edward C. "Interaction Terms in Logit and Probit Models." Economics Letters, 2003, 80, pp. 123-29.

Chernew, Michael; Cutler, David M. and Keenan, Patricia Seliger. "Increasing Health Insurance Costs and the Decline in Insurance Coverage." Health Services Research, 2005 (forthcoming).

Cutler, David M. Your money or your life: Strong medicine for America's health care system. Oxford, U.K.: Oxford University Press, 2004.

Cutler, David M. and Gruber, Jonathan. "Does Public Insurance Crowd Out Private Insurance?" Quarterly Journal of Economics, 1996, 111(2), pp. 391-430.

Cutler, David M. and McClellan, Mark. "Is Technological Change in Medicine Worth It?" Health Affairs, 2001, 20(5), pp. 11-29.

Dranove, David; Spier, Kathryn and Baker, Lau- rence. " 'Competition' Among Employers Offering Health Insurance." Journal of Health Economics, 2000, 19(1), pp. 121-40.

Farber, Henry S. and Levy, Helen. "Recent Trends in Employer-Sponsored Health Insurance Coverage: Are Bad Jobs Getting Worse?" Journal of Health Economics, 2000, 19(1), pp. 93-119.

Gruber, Jonathan. "The Impact of the Tax System on Health Insurance Decisions." Mimeo, Massachusetts Institute of Technology, July 2001.

Herring, Bradley. "Does Access to Charity Care For the Uninsured Crowd Out Private Health Insurance Coverage?" Mimeo, Yale University, 2001.

Institute of Medicine. Care without coverage: Too little, too late. Washington, DC: National Academy Press, 2002.

KPMG Survey of Employer-Sponsored Health Benefits. Menlo Park, CA: Kaiser Family Foundation, 1988, 1989, 1998.

Kaiser Family Foundation. Health research and educational trust survey of employersponsored health benefits. Menlo Park, CA: Kaiser Family Foundation, 1999.

Mann, Joyce; Melnick, Glenn; Bamezai, Anil and Zwanziger, Jack. "A Profile of Uncompensated Hospital Care 1983-1995." Health Affairs, 1997, 6(4), pp. 223-32.

Pauly, Mark V. and Herring, Bradley. Pooling health insurance risks. Washington, DC: AEI Press, Washington, DC, 1999.

Phelps, Charles. Health economics. New York: Addison Wesley, 1997.

Rask, Kevin and Rask, Kimberly. "Public Insurance Substituting for Private Insurance: New Evidence Regarding Public Hospitals, Uncompensated Care Funds, and Medicaid." Journal of Health Economics, 2000, 19(1), pp. 1-31.

Sheiner, Louise. "Health Care Costs, Wages, and Aging." Mimeo, Federal Reserve Board of Governors, Washington, DC, 1997.

Simon, Kosali. "The Effect of State Insurance Regulations on the Price and Availability of Health Benefits in Small Firms." Michigan State University Econometrics and Theory Working Paper Series No. 2001, 2002. 